\title{
Challenge of smile rehabilitation in case of dental fluorosis
}

\begin{abstract}
Establishing a patient who lost dental aesthetic appearance is one of the most important topics for contemporary dentistry. Apart from the conventional treatment modalities for the same, several options are available today with better techniques and materials. The present case report describes a 21-years old girl who had stained teeth with dental fluorosis and she desired aesthetic treatment for the same. Ceramic veneers yielded a good aesthetic and functional outcome.
\end{abstract}

Keywords: veneers, dental fluorosis, aesthetic approach, bonding
Volume 9 Issue 2 - 2018

\section{Anissa Ben Moussa, Imen kalghoum, Rahma Gazbar, Dalenda Hadyaoui, Mounir Cherif}

Department of Dental medicine, University of Monastir, Tunisia

Correspondence: Imen kalghoum, Department of Dental medicine, University of Monastir, Tunisia,

Email dalendaresearch@gmail.com

Received: October 24, 2017 | Published: March 09, 2018

\section{Introduction}

Dental fluorosis also termed mottled enamel ${ }^{1}$ is an extremely common $^{2}$ disorder, characterized by hypomineralization of tooth enamel caused by ingestion of excessive fluoride during enamel formation. ${ }^{2}$ Fluorosis first attracted attention in the early 20th century. Researchers were surprised by prevalence of what was called 'colorado Brown stain' ${ }^{3,4}$ Poor interlocking of crystals accounts for the increased porosity of enamel and thus the subsequent optical and physical changes. ${ }^{5,6}$

Nowadays, several treatment modalities are available with better techniques and materials. Ceramic veneers were first introduced in around $1938^{7,8}$ and have gained increasing popularity ever since as an esthetic and less invasive solution for discoloration. Porcelain veneers have been said to have high survival rates and good clinical success having excellent biocompatibility with gingival and periodontal tissues. ${ }^{910}$ The present case report describes a 21-year-old girl who had stained teeth, attributable to dental fluorosis and she desired aesthetic treatment for the same. A multistep treatment process involving ceramic veneers and conservative treatment. The execution of the planned treatment yielded a good aesthetic and functional outcome.

\section{Case presentation}

A 21 years old female patient was referred to the prosthetic department in the dental clinic of Monastir with chief complaint of unsightly smile due to stained teeth. Her medical history was non contributory. Intraoral examination revealed stained right central incisor with 'white spot', discolored right lateral incisor and canine with a yellowish brown colour. The left lateral incisor and canine had the same lesions without pitting.

Dean's fluorosis index was first published by H. Trendy. The index after two changes, appearing in its final form in 1942. An individual's fluorosis score is based on the most severe form of fluorosis found on two or more teeth.

In our case, It's score 4 so moderate fluorosis: Brown stain is frequently a disfiguring feature (Figure 1) (Figure 2). The preparatory stage of the treatment started with aesthetic analysis photographs, study models and preliminary shade selection. The various treatment modalities for dental fluorosis, were classified according to the 'therapeutic gradient' of Gill Tirlet and Jean Pierre Attal, ${ }^{9}$ including polishing, microabrasion, dental bleaching, composite veneers, porcelain and full veneer crowns. Hence, external whitening was offred to our patient during two weeks without any improvement. So It was decided to place ceramic veneers on the lateral incisors and canines, on the right central incisor a conservative treatment by 'micro-abrasion' was decided as a relatively low risk intervention.
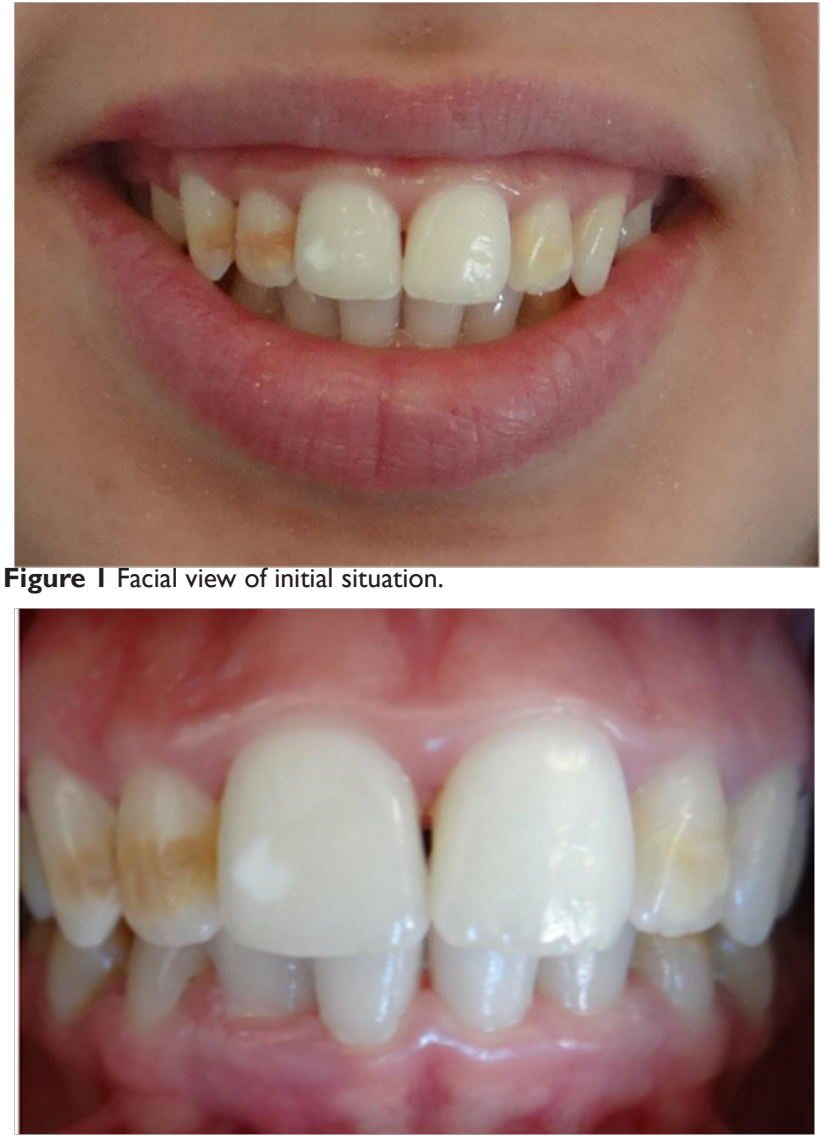

Figure 2 Intra oral views Tooth preparation

Tooth was prepared within the enamel whenever possible. Whereas enough thickness for the porcelain was provided to give sufficient fracture resistance and not to over contour the final restoration. A definite finishing line was designed allowing the ceramist to perform a veneer with normal emergence from gingival margin. ${ }^{10}$ Tooth preparation was started by labial preparation with a $0.5 \mathrm{~mm}$ depth cutting diamond point and the depth grooves were 
marked with non-water-soluble ink. There are several methods of attaining the reduction required with the preparation. ${ }^{10,11}$

Use of preparation template or silicone putty index. The use of depth cutters or grooves and dimples allows accurate judgment of depth. Proximal preparation was not carried out and the contacts were not involved. In certain situations, breaking the contact may be necessary to change for example the shape or position of teeth; this allows the ceramist freedom to adjust the contours and position of the teeth. About the cervical margin, a chamfer design with a depth of $0.5 \mathrm{~mm}$, the depth of preparation is usually influenced by dyschromia. This depth allows the veneer to reproduce natural tooth contours and not to be over contoured, furthermore, a simple seating and minimizes stress enhancing the future resistance of the ceramic. In order to reproduce the natural tooth color, the margins were sub-gingival and oral hygiene instructions should be extremely respected (Figure 3 ). ${ }^{12}$ After adequate gingival retraction, (Figure 4) a two step dual impression was made and sent to the laboratory for fabrication of lithium disclicate( IPS e max) veneers.

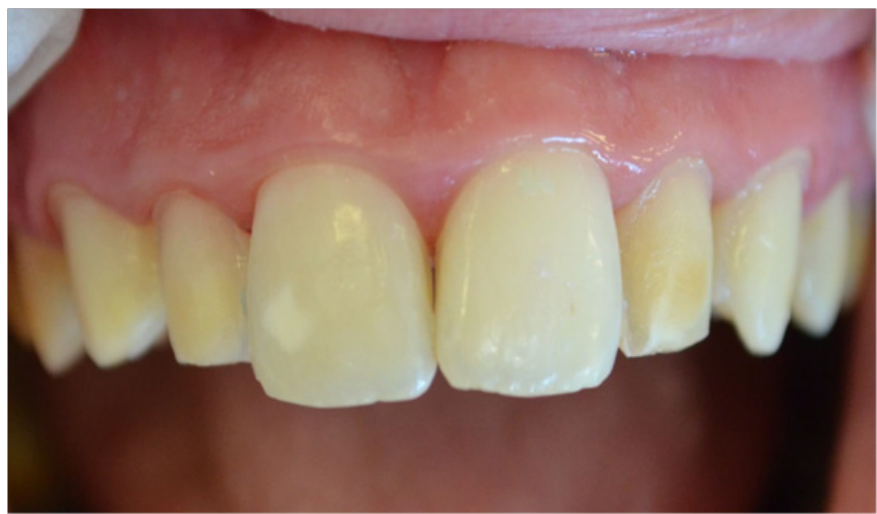

Figure 3 Tooth preparations.

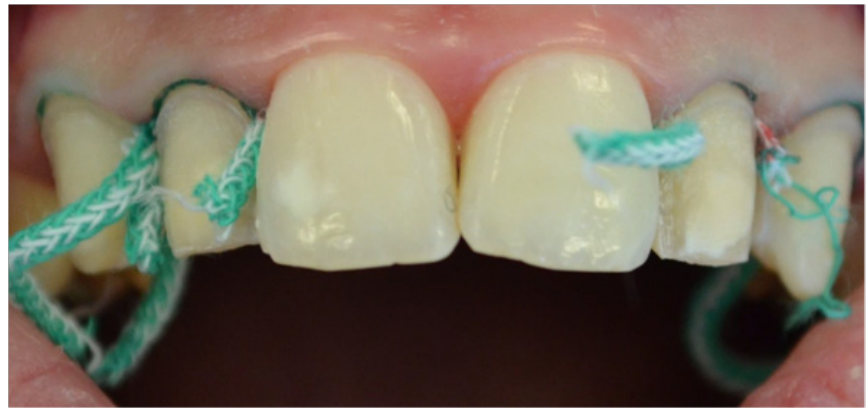

Figure 4 Gingival retraction.

\section{Terial selection}

IPS e max Cad is a lithium discilcate glass ceramic with flexural strength of about $400 \mathrm{MPA},{ }^{13}$ and it's an etchable ceramic and permits ((a strong and durable resin ceramic bond. Hence, it was selected for its optical properties, excellent flexural strength, and because it is available in different translucencies and opacities allowing the ceramist better colour masking of fluorisis. ${ }^{14}$ Ceramic veneers were CAD designed by coping the contours from the diagnostic wax-up. Cut back and layering can be done if adequate space is available. A small cut back can be made to increase the incisal translucency and internal characteristics (Figure 5). A prospective clinical study evaluating the clinical performance of lithium discilcate veneers shows a success (not requiring intervention) of $92 \%$ at 5 years and $64 \%$ at 10 years. ${ }^{15}$ According to the systematic review of Sailer, the 12 studies reporting a lithium disclicate renforced glass ceramics showed an estimated 5- year survival rate of 96.6 which was similar to the survival of metal ceramic crown. ${ }^{16}$

\section{Try in of veneers}

Veneers were individually checked intra-orally to control the complete seating, gingival margins adaptation, gingival embrasure opening, and static and dynamic occlusion.

Then, shade and esthetics were well checked.

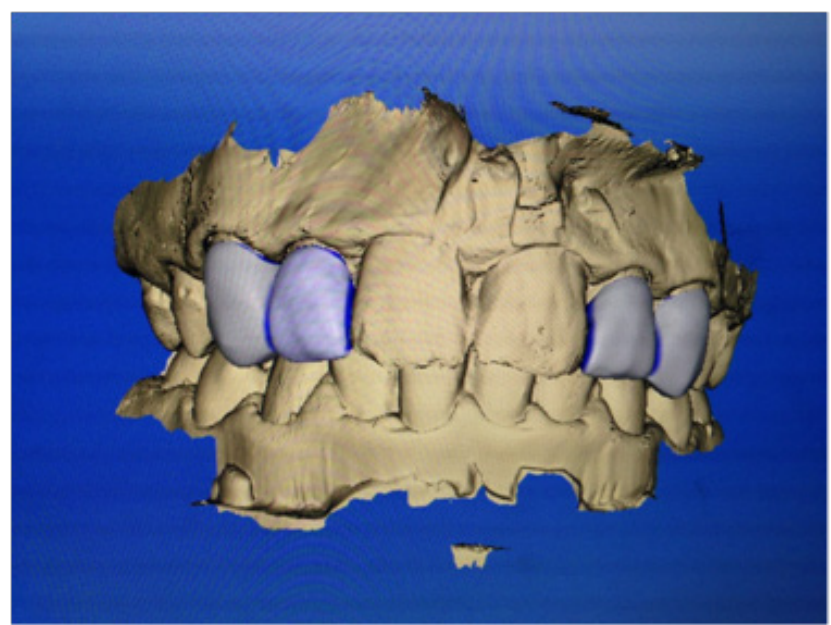

Figure 5 CAD

\section{Bonding of veneers}

Since the patient was happy and had approved the final aesthetics. The veneers were prepared for bonding. They must be at first etched with hydrofluoric acid for 20 second, allowing a micro-mechanical bond. The acid was then thoroughly cleaned with air-water spray. Silane was applied to the fitting surface which helps to provide a chemical covalent bond to the ceramic. After the veneer should be blown with air to evaporate my remaining solvent (Figures 6A-6D).

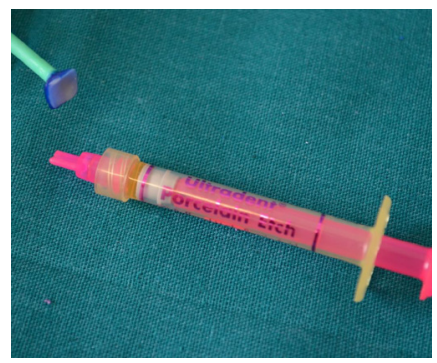

Figure 6A

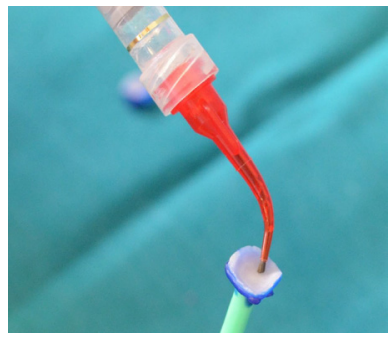

Figure 6B

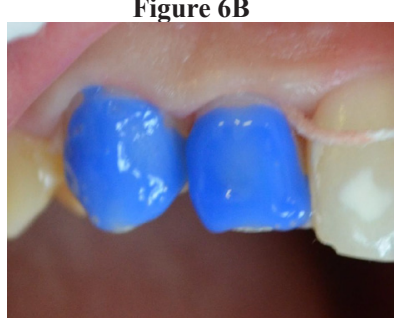

Figure 6C 


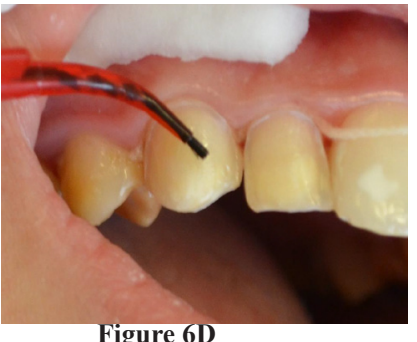

Figure 6D

To minimize contamination from saliva and blood, the application of rubber dam is fortly recommended. Light curing composite resin were used for bonding. Studies affirmed that the colour stability of that composite resin is much better compared to dual chemical cure composites.

Teeth were etched with phosphoric acid and adhesive was applied. Bonding of veneers was carried out following the predetermined lutting sequence. It's very important to control the exactly seating and that veneers don't occupying any space meant for the adjacent veneer. The lutting cement was intra-orally light cured for 1 to 2 seconds and excess was carefully removed, flowed by thorough curing of the lutting agent. If the bonding procedure was completed smoothly with a well fitting veneer. It's preferred it not use a rotary instrument to finish the margins (Figure 7). Periodic follow-up was scheduled to evaluate the gingival health and patient comfort and satisfaction

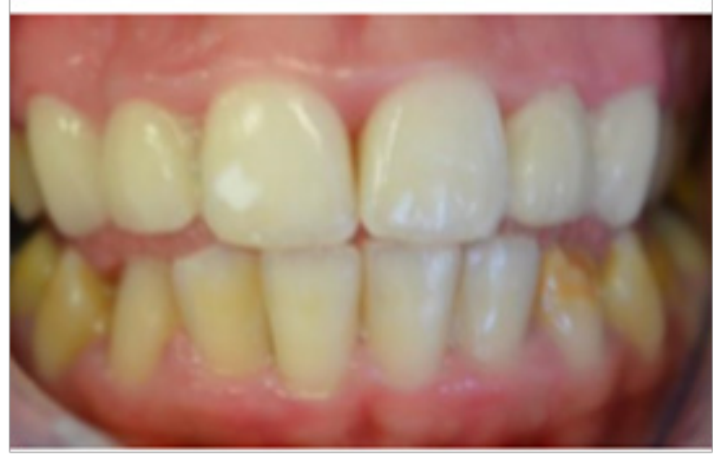

Figure 7a Final situation

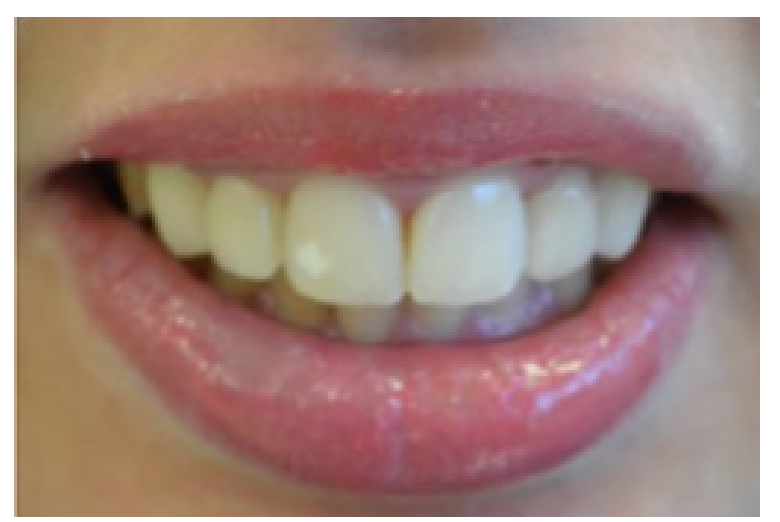

Figure 7b Smile

\section{Conclusion}

Dental fluorosis is a common problem affecting the aesthetic, psychology and confidence of the patient, a part from the conventional treatment modalities; various treatment options are available today. This case was successfully managed by the combined use of porcelain veneers and microabrasion to give a shining a deserved smile. The long term success of ceramic veneers depends on a careful case selection and diagnostic approach, as well as an appropriate tooth preparation and adhesive bonding procedure.

\section{Acknowledgements}

None.

\section{Conflict of interest}

Authors declare there is no conflict of interest in publishing the article.

\section{References}

1. Arbab Chirani R, Foray H. Dental fluorosis: etiological diagnosis. Archives de pédiatrie. 2005;12(3):284-287.

2. Sixou JL, Bailleul-forestier I. Recommandation sur la prescription des fluorures de la naissance a' l'adolescence. J Odontol Stomatol Pediatr. 2004;11(3):157-6.

3. Nelly Molina-Frechero, Martina Nevarez-Rascón, Alfredo NevarezRascón, et al. Impact of dental Fluorosis, socioeconomic status and selfPerception in sdolescents exposed to a high level of fluoride in water. Int J Environ Res. Public Health. 2017;14(1)pii:E73.

4. Maud DENISa, Anthony Atlan, Elsa Vennat, et al. White defects on enamel: diagnosis and anatomopathology: two essential factors for proper treatment (part 1). International Orthodontics. 2013;11(2):139165.

5. Limeback H,Vieira AP, Lawreuch H. Improving esthetically objectionable human enamel fluorosis with a simple microabrasion technique; Eur $J$ Oral sci. 2006;114 Suppl 1:123-126.

6. Fathi Matouk, et al. Actualités odonto-stomatologiques. 1998;203:315320 .

7. Peumans M, Meebeek CV, Lambrechts P, et al. Porcelain veneers: areview of the literature. J Dent. 2000;28(3):163-177.

8. Blatz MB, Sadan A, Kern M. Resin-ceramic bonding: a review of the literature. J Prosthet Dent. 2003;89(3):268-74.

9. Attal JP, Tirlet G. Le gradient thérapeutique: un concept médical pour les traitements esthétiques. Inf Dent. 2009;2561(8):41-42.

10. Christopher CK Ho, Brad Gobler. Porelain veneers: treatment guidelines for optimal aesthetics. Australasian Dental Practic. 2011.

11. Calamia JR. The etched porcelain veneer technique. NY State Dent J. 1988;54(7):48-50.

12. Zarone F, Apicella D, Sorrentino R, et al. Influence of tooth preparation design on the stress distribution in maxillary central incisors restored by means of alumina porcelain veneers: a 3D- finite element analysis. Dent Mater. 2005;21(12):1178-118.

13. Conard H J, w j, Seongand IJP. Current ceramic materials and systems with with clinical recommendations: a systematic review. Prosthetic dent. 2007;98(5):389-404.

14. Jacopo Castelnuovo. Les facettes céramiques: critères de fiabilité. Rev Odont Stomat. 2008;37:287-315.

15. Fabbr G, zarone F, Dellificorelli G, et al. Clinical evaluation of 860 anterior a,d posterior lithium disilicate restorations retrospective study with a mean follow-up of 3years and and a maximum observational period of 6years. Int J Periodontics Restorative Dent. 2014;34(2):16577.

16. Sailer I, Makarov NA, Thomas DS, et al. All ceramic or metal-ceramic tooth supported fixed dental prostheses (FDPs), Asystematic review of the survival and complication rates. Dent mater. 2016;32(12):389-390. 